\title{
Influence of sex on outcomes after percutaneous coronary intervention in patients over 75 years of age with coronary heart disease
}

This article was published in the following Dove Press journal:

Clinical Interventions in Aging

23 October 2014

Number of times this article has been viewed

Yuqi Liu*

Xin $\mathrm{Hu}^{*}$

Qiao Xue

Yusheng Zhao

Yu Wang

Lei Gao

Institute of Geriatric Cardiology, Chinese PLA General Hospital, Beijing, People's Republic of China

*These authors contributed equally to this work
Correspondence: Lei Gao Institute of Geriatric Cardiology,

Chinese PLA General Hospital, 28 Fuxing Road, Beijing 100853, People's Republic of China

Tel +86 I0 55499339

Fax +86 I0 55499339

Email nkgaolei2010@126.com
Background: This study aimed to investigate whether there were sex differences in in-hospital and long-term outcomes for elderly patients over 75 years of age undergoing percutaneous coronary intervention for coronary heart disease.

Methods: Consecutive patients aged $\geq 75$ years who underwent percutaneous coronary intervention at a single center in the People's Republic of China from January 2005 to December 2010 were included in this cohort study. Clinical characteristics and in-hospital and long-term outcomes were compared between men and women.

Results: A total of 465 patients (34.8\% women, mean age $78.5 \pm 3.2$ years) were recruited. Men had a higher prevalence of ST elevation myocardial infarction but were less likely to have heart failure than women $(P<0.05)$. Similar rates of successful in-hospital procedures and deaths were observed in men and women. After a mean follow-up of 3 years, no significant differences were observed between men and women in mortality $(12.5 \%$ versus $8.0 \%, P=0.151)$, myocardial infarction ( $1.4 \%$ versus $2.7 \%, P=0.368)$, target vessel revascularization $(6.1 \%$ versus $4.7 \%, P=0.540)$, or cerebral vascular disease $(7.9 \%$ versus $6.0 \%, P=0.472)$. Cox proportional hazards analysis revealed that sex was not independently associated with either in-hospital mortality or long-term mortality.

Conclusion: In elderly patients over 75 years of age, sex influences the prognosis after percutaneous coronary intervention for coronary heart disease.

Keywords: percutaneous coronary intervention, elderly, sex

\section{Introduction}

Coronary artery disease is the leading cause of death for both men and women worldwide, and percutaneous coronary intervention (PCI) has become a frequently performed therapeutic procedure for coronary artery disease since its first application by Gruntzig in $1977 .{ }^{1}$ It has been estimated that over 2 million coronary angioplasty procedures are performed annually around the world. ${ }^{2}$ Women undergoing PCI were reported to have a higher risk of adverse outcomes than men, ${ }^{3,4}$ but most of the studies were performed in the early to mid 1990s. Since that time, advances in angioplasty equipment and techniques, combined with oral antiplatelet therapy and glycoprotein IIb/ IIIa inhibitors, have improved outcomes in both men and women. As a result, the sex gap in outcomes after PCI has narrowed. ${ }^{5,6}$ In contemporary practice of interventional cardiology, almost $25 \%$ of all PCIs are performed in patients aged $\geq 75$ years and $12 \%$ in those aged $\geq 80$ years. ${ }^{7,8}$ In general, bleeding was higher among women undergoing PCI. Sex was an independent predictor of overall major adverse coronary events at 30 days, but not of death, and there was no difference in major adverse coronary events 
between women and men at 12-month follow-up. ${ }^{9}$ However, the influence of sex on in-hospital and long-term outcomes in very elderly patients (over 75 years) has not been reported. In the present study, we compared sex-based in-hospital and long-term outcomes for elderly patients $\geq 75$ years of age after PCI.

\section{Materials and methods Patient population and data collection}

This prospective cohort study included consecutive patients aged $\geq 75$ years undergoing PCI from January 2005 to December 2010 in the Chinese PLA General Hospital in Beijing. The indications for PCI included a diagnosis of acute coronary syndrome with no contraindication for PCI or serious comorbidities, such as cancer, liver, or respiratory failure, and a diagnosis of stable angina not controlled with standard anti-ischemic pharmacological treatment. The inclusion criteria were: diagnosis of coronary heart disease; age $\geq 75$ years; and an indication for PCI. Exclusion criteria were: cancer with survival estimated as less than one year; and serious kidney, liver, or respiratory failure. Patients were stratified by sex. Baseline characteristics, procedures, and inhospital outcomes were collected in an electronic database.

Over 45 data elements were selected for analysis, including patient demographic data (eg, age, sex), risk factors (eg, smoking, diabetes), medical history (eg, number of diseased vessels, prior myocardial infarction [MI], ejection fraction), PCI indications, clinical setting, and angiographic findings. All PCI procedures were performed according to standard clinical guidelines. ${ }^{10}$ Before the procedure, all patients were treated with $300 \mathrm{mg}$ aspirin and $300 \mathrm{mg}$ clopidogrel. A heparin dose of 5,000 units was administered after sheath insertion. Qualitative and quantitative coronary angiographies were performed in all patients using standard morphological criteria to characterize baseline lesion characteristics. Quantitative angiographic analysis was performed before and after PCI. Vessel and lesion measurements were obtained using a computerized quantitative analysis system. The medical records of all patients were reviewed to determine post-procedural outcomes.

\section{Definitions}

The endpoint of this study was major adverse coronary and cerebral events, defined as cardiac death, non-fatal MI, target vessel revascularization, and cerebral artery events. Hypercholesterolemia was defined as a fasting serum cholesterol level $>5.5 \mathrm{mmol} / \mathrm{L}$ or use of lipid-lowering therapy at the time of the procedure. Hypertension was defined as blood pressure $>140 / 90 \mathrm{mmHg}$ or the use of antihypertensive medications. MI was diagnosed by raised creatine kinase MB greater than three times the upper limit of normal. Multivessel disease was defined as the presence of $>50 \%$ stenosis in two or more major epicardial coronary arteries. Target vessel revascularization was defined as repeat revascularization of a lesion in the same epicardial vessel treated in the index procedure. Target lesion revascularization was defined as a repeat intervention in the stent or in the $5 \mathrm{~mm}$ segments proximal or distal to the stent. Procedural success was defined as a minimum reduction in stenosis diameter to less than $20 \%$ after PCI, with no death, MI, or coronary artery bypass grafting surgery. Death was defined as death from any cause. Major bleeding complications were defined as a need for transfusion, a reduction in hemoglobin of more than $40 \mathrm{~g} / \mathrm{L}$, or intracranial or retroperitoneal hemorrhage. Patients reporting cigarette use during the year prior to examination were considered smokers. Diabetes mellitus was defined as hyperglycemia, requiring antidiabetic drugs or fasting blood sugar over $126 \mathrm{~g} / \mathrm{dL}$. In patients undergoing staged procedures, treated segments from both procedures were grouped together to prevent misclassification.

\section{Follow-up}

Follow-up information for all patients discharged from the hospital was obtained by planned telephone interviews conducted by an experienced data technician. Data regarding vital status such as recurrence of angina, acute MI, revascularization, and stroke were collected. In the event of death, the patient's family reported the patient's health status preceding the event, and the death certificate was requested. The medical records in the PLA General Hospital in Beijing were reviewed for all patients who were followed up at this institution, and verification of events occurring at other hospitals was obtained from the attending physicians. Routine review and editing of out-of-range data were performed to ensure quality of data received after discharge from hospital.

\section{Statistical analysis}

Categorical data are presented as percentages and compared using the chi-square or Fisher's exact test as appropriate. Continuous variables are presented as the mean \pm standard deviation and compared using the Student's $t$-test or analysis of variance. Survival analysis was performed with the Kaplan-Meier method for each group and compared using the log-rank test. The association between sex and all-cause mortality was determined by multivariable Cox proportional 
hazard regression analyses to adjust for differences in baseline characteristics. Potential confounders were entered into models if they were clinically relevant or showed differences between groups in the univariable analysis and $P<0.10$. All calculated $P$-values were two-sided and a $P$-value $<0.05$ was considered to be statistically significant. Statistical Package for the Social Sciences version 17.0 software (SPSS Inc, Chicago, IL, USA) was used for all statistical analyses.

\section{Results}

\section{Baseline characteristics of study population}

There were 503 consecutive coronary heart disease patients aged $\geq 75$ years who underwent PCI from January 2005 to December 2010. Of these, 465 (92.4\%) who had undergone follow-up were included in this study. There were $303(65.1 \%)$ men and 162 (34.9\%) women, with a mean age of $78.5 \pm 3.2$ years. The baseline clinical characteristics for the study population according to sex are shown in Table 1. There were no differences between men and women with respect to age, hypertension, diabetes, hyperlipidemia, smoking, chronic bronchial disease, left ventricular ejection fraction, or estimated glomerular filtration rate. Men were more likely to have a history of cerebral vascular disease, MI, and bypass surgery. The proportion of previous PCI was similar between the sexes. Although no significant differences were observed between men and women in unstable angina and non-ST elevation MI, men presented more often with ST elevation MI but less often with heart failure than women.

\section{Procedural characteristics}

Table 2 summarizes the angiographic and procedural characteristics. There were no significant differences in the number of diseased coronary vessels between men and women. The distribution characteristics of lesions were similar in the two groups, except for lesions in the left anterior descending coronary artery, which were more frequent in men $(P=0.037)$. There were no significant differences between the two groups as to multivessel disease or number and distribution of target vessels. Stent placement, including multistents, staged stenting, and number of stents, was almost equal in both sexes. The use of stents and glycoprotein IIb/IIIa receptor inhibitors was also similar. An intra-aortic balloon pump was placed in $3.3 \%$ of men compared with $2.5 \%$ of women $(P=0.829)$.

\section{Procedural success and in-hospital outcomes}

The procedural success rate and in-hospital outcomes are shown in Table 3. The PCI success rate was $94.4 \%$ in both groups. No significant differences were noted in the rate of complete revascularization among men and women $(45.2 \%$ versus $46.3 \%, P=0.900)$. The in-hospital mortality for men

Table I Baseline clinical characteristics

\begin{tabular}{|c|c|c|c|}
\hline Characteristic & $\begin{array}{l}\text { Men } \\
n=303(63.5 \%)\end{array}$ & $\begin{array}{l}\text { Women } \\
n=162(36.5 \%)\end{array}$ & P-value \\
\hline Age, years (mean $\pm S D$ ) & $78.4 \pm 3.2$ & $78.7 \pm 3.2$ & 0.269 \\
\hline Hypertension & $228(75.2)$ & $130(82.0)$ & 0.115 \\
\hline Diabetes & $100(33.3)$ & $67(4 I .5)$ & 0.091 \\
\hline Hyperlipidemia & $160(52.8)$ & $78(48.1)$ & 0.389 \\
\hline Current smoker & $62(20.5)$ & $45(27.8)$ & 0.095 \\
\hline Chronic bronchial disease & $40(13.2)$ & $14(8.6)$ & 0.190 \\
\hline Cerebral vessel disease & $98(32.3)$ & $17(10.5)$ & $<0.001 *$ \\
\hline \multicolumn{4}{|l|}{ Previous cardiac history } \\
\hline Previous myocardial infarction & $72(23.8)$ & $24(18.5)$ & $0.03 I^{*}$ \\
\hline Previous $\mathrm{PCl}$ & $4 I(13.5)$ & $21(13.0)$ & 0.641 \\
\hline Previous bypass surgery & $35(11.6)$ & $7(4.3)$ & $0.015^{*}$ \\
\hline \multicolumn{4}{|l|}{ Acute coronary syndrome } \\
\hline Unstable angina & $184(60.7)$ & $106(65.4)$ & 0.369 \\
\hline NSTEMI & $4 \mid(13.5)$ & $18(1 \mathrm{I} .1)$ & 0.547 \\
\hline STEMI & $63(20.8)$ & $19(11.7)$ & $0.020 *$ \\
\hline NYHA (III-IV) & $33(10.9)$ & $30(18.5)$ & $0.03 I^{*}$ \\
\hline Left ventricular ejection fraction (\%) & $62.9 \pm 10.2$ & $61.3 \pm 10.0$ & 0.764 \\
\hline eGFR (L/min/I.73 m³) & $76.4 \pm 23.5$ & $77.4 \pm 24.6$ & 0.843 \\
\hline Serum creatinine & $75.2 \pm 20.9$ & $73.1 \pm 22.3$ & 0.291 \\
\hline
\end{tabular}

Note: $* p<0.05$.

Abbreviations: eGFR, estimated glomerular filtration rate; PCI, percutaneous coronary intervention; NSTEMI, non-ST elevation myocardial infarction; STEMI, ST elevation myocardial infarction; NYHA, New York Heart Association Functional Classification. 
Table $2 \mathrm{PCl}$ characteristics and in-hospital treatments

\begin{tabular}{|c|c|c|c|}
\hline & $\begin{array}{l}\text { Men } \\
63.5 \%(n=303)\end{array}$ & $\begin{array}{l}\text { Women } \\
36.5 \%(n=162)\end{array}$ & $P$-value \\
\hline Number of diseased vessels* & $2.1 \pm 0.8$ & $2.0 \pm 0.8$ & 0.942 \\
\hline \multicolumn{4}{|l|}{ Lesions } \\
\hline LAD & $81.5(247)$ & $72.8(118)$ & 0.037 \\
\hline LCX & $60.7(184)$ & $62.3(101)$ & 0.809 \\
\hline RCA & $64.7(196)$ & $59.3(96)$ & 0.292 \\
\hline LM & $13.9(42)$ & $9.3(15)$ & 0.196 \\
\hline Multivessel disease & $71.6(217)$ & $68.5(111)$ & 0.554 \\
\hline Number of target vessels & $1.4 \pm 0.6$ & $1.4 \pm 0.6$ & 0.753 \\
\hline \multicolumn{4}{|l|}{ Target vessels } \\
\hline LAD & $50.8(154)$ & $51.2(83)$ & 0.989 \\
\hline LCX & $35.6(108)$ & $4 I .3(67)$ & 0.266 \\
\hline RCA & $48.8(148)$ & $40.7(66)$ & 0.115 \\
\hline LM & $7.6(23)$ & $6.2(10)$ & 0.705 \\
\hline Multilesion stenting & $39.6(120)$ & $42.0(68)$ & 0.691 \\
\hline Number of stents & $2.1 \pm 1.1$ & $2.1 \pm 1.3$ & 0.678 \\
\hline Staged stenting & $12.2(37)$ & $14.8(24)$ & 0.516 \\
\hline IABP & $3.3(10)$ & $2.5(4)$ & 0.829 \\
\hline Glycoprotein Ilb/Illa inhibitor & $22.7(69)$ & $19.7(32)$ & 0.525 \\
\hline
\end{tabular}

Note: *Mean \pm standard deviation.

Abbreviations: LAD, left anterior descending; LCX, left circumflex; RCA, right coronary artery; LM, left main; IABP, intra-aortic balloon pump; PCI, percutaneous coronary intervention.

and women was $1.3 \%$ and $3.1 \%$, respectively $(P=0.335)$. Of the four men who died, three had cardiogenic shock on admission before PCI, and one had post-PCI cardiogenic shock. Of the five women who died, three were in cardiogenic shock on admission before PCI, one had retroperitoneal bleeding post-PCI, and one had post-PCI cardiogenic shock. There was no statistically significant difference in the frequency of emergency bypass surgery, MI, or stroke between men and women. The incidence of major vascular complications and major bleeding did not differ between the groups.

\section{Long-term outcomes}

The mean follow-up duration was $36.2 \pm 21.8$ (range 6-78) months, with follow-up completed in $92.3 \%$ of patients. The mortality at a mean follow-up of 3 years was $12.5 \%$ for men and $8.0 \%$ for women $(P=0.151)$. The cardiac death rate was $7.2 \%$ for men and $7.3 \%$ for women. Figure $1 \mathrm{~A}$ and B show the cumulative overall survival rate and cumulative disease-free survival rate for men and women. The cumulative overall survival rate for men versus women at one, 2 , 3 , 4 , and 5 years of follow-up was $95 \%$ versus $94 \%, 93 \%$ versus $93 \%, 92 \%$ versus $87 \%, 83 \%$ versus $89 \%$, and $82 \%$ versus $85 \%$, respectively (Figure 1A). The cumulative disease-free survival rate for men versus women at one, 2 , 3 , 4 , and 5 years was $94 \%$ versus $91 \%, 88 \%$ versus $86 \%$, $81 \%$ versus $80 \%, 78 \%$ versus $78 \%$, and $71 \%$ versus $70 \%$, respectively (Figure 1B). In the 429 patients followed up, there were no significant differences in cumulative overall survival rate (log-rank test, $P=0.159$ ) or disease-free survival rate (log-rank test, $P=0.429$ ) between men and women. Long-term outcomes are shown in Table 4 . The overall major adverse coronary and cerebral events $(22.6 \%$ versus $20.1 \%$ in men and women, respectively, $P=0.984$ ), including cardiac death, non-fatal acute MI, target vessel revascularization and cerebral vascular events, showed no significant difference. Although both groups showed similar complete

Table 3 Procedure success rate and in-hospital outcomes

\begin{tabular}{|c|c|c|c|}
\hline & Men & Women & $P$-value \\
\hline & $63.5 \%(n=303)$ & $36.5 \%(n=162)$ & \\
\hline Procedure success rate & $94.4(286)$ & $94.4(153)$ & 0.851 \\
\hline Death in hospital & $1.3(4)$ & $3.1(5)$ & 0.335 \\
\hline Complete revascularization & $45.2(137)$ & $46.3(75)$ & 0.900 \\
\hline \multicolumn{4}{|l|}{ Complications } \\
\hline Vascular complications & $7.9(24)$ & $7.4(12)$ & 0.987 \\
\hline Major bleeding & $3.4(10)$ & $3.1(5)$ & 0.879 \\
\hline
\end{tabular}


A

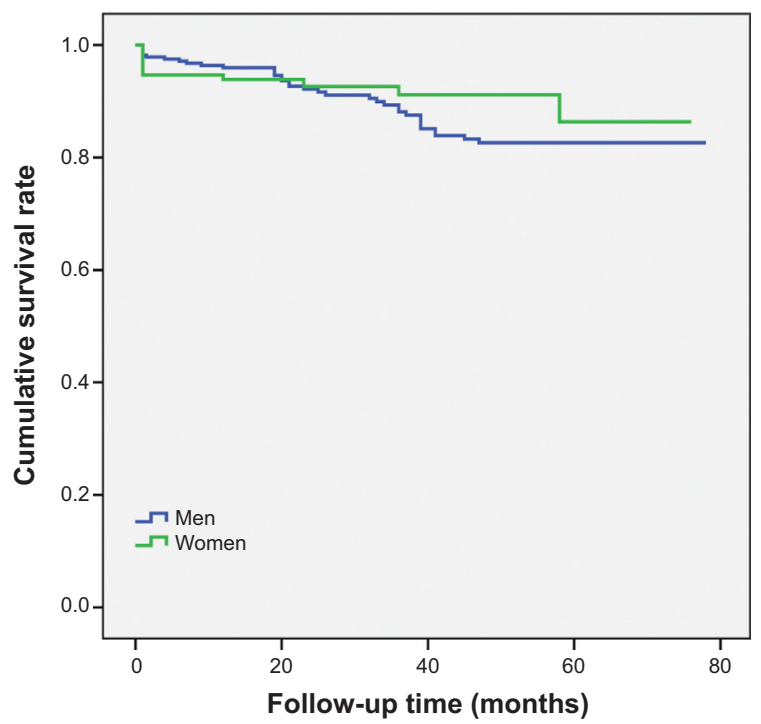

B

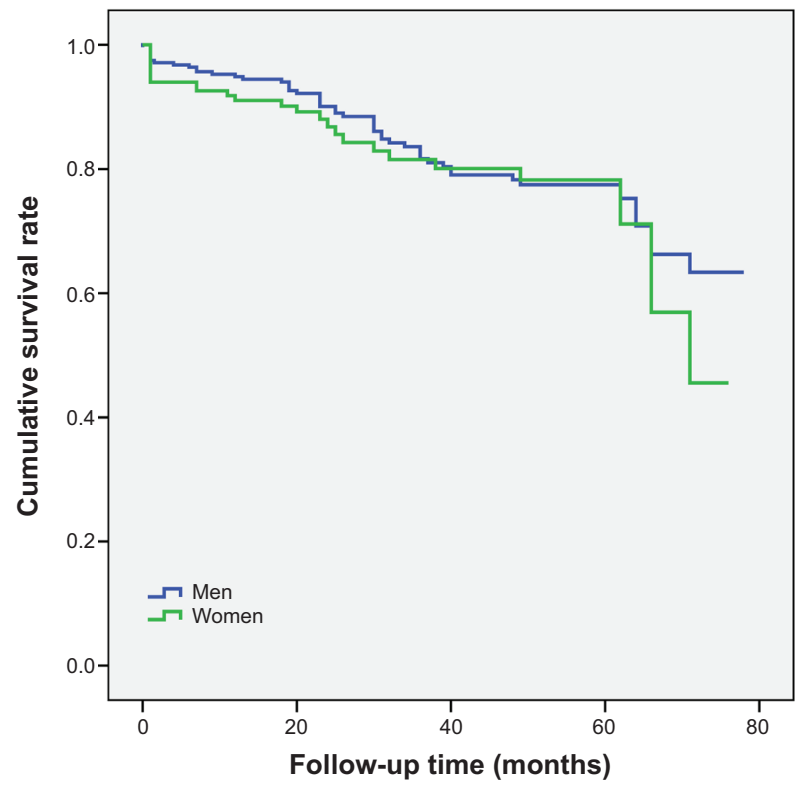

Figure I Kaplan-Meier curves for overall survival and disease-free survival.

Notes: Estimated survival stratified by sex was analyzed by the Kaplan-Meier method, followed by log-rank analysis. No significant differences were observed between men and women in $(\mathbf{A})$ overall survival rate (log-rank test, $P=0.159)$ and $(\mathbf{B})$ disease-free survival rate (log-rank test, $P=0.429)$.

revascularization rates, men presented with a significantly higher rate of angina recurrence within 6 months after PCI (56.3\% versus $43.3 \%, P=0.011)$. The readmission rate was similar for both sexes $(29.7 \%$ versus $29.3 \%, P=0.928)$.

\section{Multivariate analysis}

Multivariable Cox proportional hazard regression analyses were used to identify independent predictors of the composite of mortality rate. The variables associated with increased in-hospital or long-term mortality were increasing age, cerebral vascular disease, acute coronary syndrome, previous cardiac history (including previous MI and previous bypass surgery), and angiographic characteristics. The independent predictors of long-term survival are presented in Table 5. The results showed that cerebral vessel disease, heart failure, and multivessel disease are independent predictors for death in patients with acute coronary syndrome. However, sex was not an independent risk factor for in-hospital or long-term mortality after PCI.

\section{Discussion}

Early studies evaluating sex differences in outcomes of PCI overall demonstrated higher complication and adverse outcomes rates in women., ${ }^{3,4}$ The earlier National Heart, Lung, and Blood Institute PCI registry indicated female sex to be independently predictive of in-hospital mortality. ${ }^{4}$ The higher prevalence of adverse outcomes in women was attributed largely to older age, smaller coronary artery diameter, and more prevalent comorbid conditions, including diabetes mellitus, hypertension, hypercholesterolemia, peripheral vascular disease, and heart failure. However, accumulating evidence indicates that there are no differences regarding

Table 4 Long-term outcomes*

\begin{tabular}{llll}
\hline & Men 65.0\% (n=279) & Women 35.0\% (n=I50) & $P$-value \\
\hline Death & $12.5(35)$ & $8.0(12)$ & 0.151 \\
MACCE & $22.6(63)$ & $20.1(31)$ & 0.984 \\
$\quad$ Cardiac death & $7.2(20)$ & $7.3(11)$ & 0.190 \\
Non-fatal MI & $1.4(4)$ & $2.7(4)$ & 0.368 \\
TVR & $6.1(17)$ & $4.7(7)$ & 0.540 \\
Cerebral vessel events & $7.9(22)$ & $6.0(9)$ & 0.472 \\
Angina recurrence within 6 months & $56.3(157)$ & $43.3(65)$ & 0.011 \\
Readmission & $29.7(83)$ & $29.3(44)$ & 0.928 \\
\hline
\end{tabular}

Note: *Follow-up period was 6-78 months.

Abbreviations: TVR, target vessel revascularization; MACCE, major adverse coronary and cerebral events; MI, myocardial infarction. 
Table 5 Multivariate predictors of in-hospital and long-term outcomes

\begin{tabular}{|c|c|c|c|c|}
\hline \multirow[t]{3}{*}{ Variable } & \multicolumn{4}{|l|}{ Outcome } \\
\hline & \multicolumn{2}{|l|}{ In-hospital } & \multicolumn{2}{|l|}{ long-term } \\
\hline & HR (95\% Cl) & $P$-value & HR (95\% Cl) & $P$-value \\
\hline Sex & $1.12(0.75-1.43)$ & 0.235 & $1.16(0.86-1.57)$ & 0.467 \\
\hline Cerebral vessel disease & $1.53(1.12-1.95)$ & 0.102 & $1.96(1.32-2.26)$ & $<0.001$ \\
\hline Previous PCl & $1.42(1.21-1.95)$ & 0.132 & $1.05(0.76-1.31)$ & 0.621 \\
\hline Heart failure III-IV & $1.96(1.67-2.27)$ & $<0.01$ & $2.5 \mathrm{I}(2.15-2.86)$ & $<0.001$ \\
\hline Multivessel disease & $1.32(1.03-1.65)$ & 0.145 & $1.67(1.24-1.98)$ & $<0.001$ \\
\hline
\end{tabular}

Abbreviations: $\mathrm{Cl}$, confidence interval; $\mathrm{HR}$, hazard ratio; $\mathrm{PCl}$, percutaneous coronary intervention.

in-hospital or long-term mortality after PCI in elderly women and men. ${ }^{11}$ In the present study, we compared the sex-based in-hospital and long-term outcomes after PCI in patients aged older than 75 years, and demonstrated that, for very elderly patients undergoing PCI, men and women have equivalent in-hospital and long-term outcomes, and female is an independent risk factor neither for in-hospital outcomes nor long-term outcomes.

More than 1.2 million PCIs are performed annually in the USA. An estimated 33\% of PCIs are performed in women. ${ }^{12}$ Compared with men, women undergoing PCI were found to be 5 years older and to have a higher prevalence of hypertension, diabetes, and other comorbidities. ${ }^{13}$ However, in this study, there was no difference in comorbidities between elderly men and women, which may be related to greater concern over the health status of women in recent years. Women in the USA are less likely to have had a history of MI, PCI, or coronary bypass graft surgery, which is consistent with our results. In addition, at the time of PCI, they have less multivessel disease and are more likely to present with unstable angina. Women present with less ST elevation MI compared with men, have similar lesion types, less multivessel disease, and better preserved left ventricular function. ${ }^{13}$ Early reports of patients undergoing balloon angioplasty found lower procedural success rates in women. In addition, earlier registry studies showed that women had higher in-hospital mortality after PCI, even after adjusting for baseline comorbidities. ${ }^{14}$ However, recent studies reported similar procedural success rates of more than $90 \%$ in both groups. ${ }^{14} \mathrm{With}$ improvements in PCI technology and procedures, this study found no differences in procedural success rate, mortality, or complications, including vascular complications and major bleeding (see Table 3). With newer-generation stents and balloons, smaller sheath sizes and catheters, and advances in adjunctive pharmacotherapies, adjusted long-term mortality and morbidity rates after PCI have become similar between men and women. ${ }^{14}$
Berger et al studied the effect of sex on long-term mortality in a large cohort of patients undergoing PCI. They found that, despite higher-risk characteristics, female sex conferred a long-term survival advantage after PCI. ${ }^{13}$ Until now, there have only been a few studies on the very elderly population more than 75 years old. ${ }^{15,16}$ Our study showed that after an average of 3 years of follow-up, mortality was similar for women and men $\geq 75$ years undergoing PCI. After adjustment for baseline characteristics, sex was not associated with the risk of long-term mortality. Our study demonstrated significant improvement in long-term outcome after PCI in both sexes compared with older studies, and is consistent with recent observations from other centers. ${ }^{17}$

However, there are several limitations to our study. First, this study was a nonrandomized, retrospective analysis from a single, large-volume, tertiary care center, which limits its generalizability. Moreover, it is universally acknowledged that at older ages (70-90 years) most patients are female, which is inconsistent with the results of this study where two thirds of patients were male. This may be associated with the fact that female patients are reluctant to accept invasive treatment such as PCI. This type of bias cannot be controlled. Third, the treatment decisions were not randomized and the study population was relatively small, so further large cohort studies are needed.

\section{Conclusion}

In conclusion, the results of the present study demonstrate that PCI has a good success rate and acceptable mortality in patients over 75 years of age. No differences in in-hospital and long-term outcomes were observed between men and women undergoing PCI. For elderly patients, sex was not an independent risk factor for in-hospital or long-term mortality after PCI.

\section{Acknowledgment}

This work was supported by grants from the National Science Foundation of China to Yuqi Liu (Mechanisms of interaction between environmental factors and mitochondrial gene 
mutation contribute to hypertension target organ damage, 81100186/H0214).

\section{Disclosure}

The authors report no conflicts of interest in this work.

\section{References}

1. Gruntzig AR, Senning A, Siegenthaler WE. Nonoperative dilatation of coronary-artery stenosis: percutaneous transluminal coronary angioplasty. N Engl J Med. 1979;301:61-68.

2. Roger VL, Go AS, Lloyd-Jones DM, et al. Heart disease and stroke statistics - 2011 update: a report from the American Heart Association. Circulation. 2011;123:e18-e209.

3. Kelsey SF, James M, Holubkov AL, Holubkov R, Cowley MJ, Detre KM. Results of percutaneous transluminal coronary angioplasty in women. 1985-1986 National Heart, Lung, and Blood Institute's Coronary Angioplasty Registry. Circulation. 1993;87:720-727.

4. Cowley MJ, Mullin SM, Kelsey SF, et al. Sex differences in early and long-term results of coronary angioplasty in the NHLBI PTCA Registry. Circulation. 1985;71:90-97.

5. Jacobs AK, Johnston JM, Haviland A, et al. Improved outcomes for women undergoing contemporary percutaneous coronary intervention: a report from the National Heart, Lung, and Blood Institute Dynamic registry. J Am Coll Cardiol. 2002;39:1608-1614.

6. King KM, Ghali WA, Faris PD, et al. Sex differences in outcomes after cardiac catheterization: effect modification by treatment strategy and time. JAMA. 2004;291:1220-1225.

7. Rao SV, Ou FS, Wang TY, et al. Trends in the prevalence and outcomes of radial and femoral approaches to percutaneous coronary intervention: a report from the National Cardiovascular Data Registry. JACC Cardiovasc Interv. 2008;1:379-386.

8. Bauer T, Mollmann H, Weidinger F, et al. Predictors of hospital mortality in the elderly undergoing percutaneous coronary intervention for acute coronary syndromes and stable angina. Int J Cardiol. 2011;151: 164-169.
9. Al-Fiadh AH, Andrianopoulos N, Farouque O, et al; Melbourne Interventional Group. Contemporary outcomes in women undergoing percutaneous coronary intervention for acute coronary syndromes. Int J Cardiol. 2011;151:195-199.

10. Silber S, Albertsson P, Aviles FF, et al. Guidelines for percutaneous coronary interventions. The Task Force for Percutaneous Coronary Interventions of the European Society of Cardiology. Eur Heart $J$. 2005;26:804-847.

11. Malenka DJ, Wennberg DE, Quinton HA, et al. Gender-related changes in the practice and outcomes of percutaneous coronary interventions in Northern New England from 1994 to 1999. J Am Coll Cardiol. 2002;40: 2092-2101.

12. American Heart Association. Heart Disease and Stroke Statistics 2005 Update. Dallas, TX, USA: American Heart Association; 2004.

13. Berger JS, Sanborn TA, Sherman W, Brown DL. Influence of sex on in-hospital outcomes and long-term survival after contemporary percutaneous coronary intervention. Am Heart J. 2006;151:1026-1031.

14. Chiu JH, Bhatt DL, Ziada KM, et al. Impact of female sex on outcome after percutaneous coronary intervention. Am Heart J. 2004;148: 998-1002.

15. Kim YA, Jeong MH, Joo SB, et al. The percutaneous coronary intervention in elderly women over 70 years of age. Korean J Med. 2001;60: 456-462.

16. Yang B, Choi MJ, Jeong MH, et al. The effect of gender on short- and long-term clinical outcomes of percutaneous coronary intervention in Korean octogenarians. Korean Circ J. 2002;10:864-871.

17. Wong SC, Sleeper LA, Monrad ES, et al. Absence of gender differences in clinical outcomes in patients with cardiogenic shock complicating acute myocardial infarction. A report from the SHOCK Trial Registry. J Am Coll Cardiol. 2001;38:1395-1401.
Clinical Interventions in Aging

\section{Publish your work in this journal}

Clinical Interventions in Aging is an international, peer-reviewed journal focusing on evidence-based reports on the value or lack thereof of treatments intended to prevent or delay the onset of maladaptive correlates of aging in human beings. This journal is indexed on PubMed Central, MedLine,

\section{Dovepress}

CAS, Scopus and the Elsevier Bibliographic databases. The manuscript management system is completely online and includes a very quick and fair peer-review system, which is all easy to use. Visit http://www.dovepress. $\mathrm{com} /$ testimonials.php to read real quotes from published authors. 